\title{
The Impact Of Decision Power On Financial Risk Tolerance And Asset Allocation
}

John E. Gilliam, PhD, CFP®, Texas Tech University, USA

John E. Grable, PhD, CFP®' Kansas State University, USA

Vickie L. Hampton, PhD, CFP®' Texas Tech University, USA

\begin{abstract}
This research considers the impact of decision power (Blood \& Wolfe, 1960) and demographic variables within a couple's relationship on risk tolerance and portfolio risk levels. Married couples $(N=175)$ separately completed a survey consisting of the Blood and Wolfe Decision Power Index, the Survey of Consumer Finances risk tolerance question, demographic information, and selected financial variables. Unlike their husbands, the study found an effect of decision power for wives and portfolio risk level, suggesting that the wife's decision power affects portfolio risk levels. Decision power was found to be a significant factor in risk tolerance for both the husband and wife. Findings indicate that both portfolio risk levels and risk tolerance is determined by the education of the wife and not the husband. Further, a divergence in risk levels occurred when the husband owned a greater degree of assets than the wife.
\end{abstract}

Keywords: financial risk tolerance; decision power; married couples

\section{INTRODUCTION}

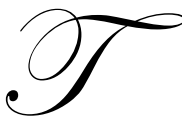

he issue of who takes the role as the definitive decision maker within a household is one which has spawned research for decades. Prior to the 1960s, traditional gender roles were based on the assumption that men held the power in the market place or the ability to work in income generating fields. As such, men typically were assumed to be the final arbitrator in household decisions that involved a meaningful financial component. Meanwhile, women controlled the day-to-day activities of maintaining the home, child rearing, and preserving relationships (Amato \& Booth, 1995; Beavers, 1972; Blood \& Wolfe, 1960). Decisions related to these activities were assumed to be made primarily by women. The general acceptance of these genderbased household decision stereotypes has gradually been replaced by a better understanding of the complex nature of household decisions made jointly.

Nearly all recent family, as well as economic, research suggests that a gender-based decision making perspective at the household level is not wholly accurate (Chaulk, Johnson, \& Bulcroft, 2003). Instead, it appears that the balance of decision-making power within a couple's relationship is influenced by factors such as common goals and marriage commitment, rather than purely on the gender of those in the relationship. That is, the general consensus suggests that "household decisions are made based on pooled resources and common preferences" (Jianakoplos \& Bernasek, 2008, p. 289) rather than solely on the relative bargaining power of one spouse, although there is some evidence to suggest that relative earnings can sometimes affect bargaining power (Bernasek \& Bajtelsmit, 2002; Lee, 2007). A gap exists in the literature however. Specifically, only a small amount of literature has been devoted to understanding how couples make financial decisions in which a risk is inherent in the choice (Chaulk et al.; Gilliam, Goetz, \& Hampton, 2008; Lai, 2010; Ulker, 2009; Yilmazer \& Lyons, 2010). The Jianakoplos and Bernasek study is one significant exception. As they noted, the issue of risk and decision making, at the couple household level, is not an unimportant topic of inquiry. Consider the enormous flow of assets that move between and among investments at the household level. The allocation of defined contribution savings for the benefit of a married couple, for example, illustrates how a greater knowledge of decision-making processes might improve portfolio returns for a married couple (Lai; Yilmazer \& Lyons). In the household financial marketplace, financial advisors have few tools to direct them as they make recommendations that impact multiple asset allocation 
decisions for married couples. The lack of tools for such advice is directly related to the paucity of research on decision power when couples are faced with a risky financial decision. Many other more mundane financial decisions also involve a risky choice in which knowledge about decision power might improve well-being at the household level. Choices about spending versus saving, the use of debt to fund expenditures, and the choice of which consumer finance products to purchase all contain an element of decision power within the couple relationship (Duda, Bruhin, Epper, \& Schubert, 2010).

This research applies the Decision Power Index (DPI) (Blood \& Wolfe, 1960) to the study of financial risk tolerance decision making. The DPI is considered a measure of power within a couple's relationship. This study reports findings from an analysis that was performed to determine the predictive power of the DPI on a couple's portfolio risk level and their risk tolerance. The conceptual framework for this research is resource theory and its application to the area of financial risk tolerance. The working hypothesis for this study is premised on the assumption that the individual who contributes the greatest resources to the marital unit has the maximum "say" in the allocation of assets in the portfolio. Resources are defined as anything which one partner can contribute to the other that can be used to satisfy or obtain the needs or goals of the other partner (Blood \& Wolfe). This hypothesis is much closer to the theoretical perspective of household decision making in the family studies field than it is to a gender-based perspective. Rather than assume that primarily because a man (or woman) contributes more financially to a household, and then assuming that this monetary power imbalance entitles the person to a greater say in financial decisions, this study, based on resource theory literature (Hesse-Biber \& Williamson, 1984), is premised on the notion that resource contributions can be made vis-à-vis a partner's relative status in relation to the percentage of income, asset ownership, and level of education. The remainder of this paper provides the context and methodology to test this hypothesis.

\section{LITERATURE REVIEW}

\section{Resource Theory}

Resource theory was first developed by Wolfe (1959) and extended by Blood and Wolfe (1960). The foundation of the theory suggests that the individual who is able to contribute the greatest amount of resources (e.g., financial, emotional, etc.), which enables others to fulfill their needs and attain their goals, is recognized as having the greatest power (Blood \& Wolfe, 1960; Blumstein \& Schwartz, 1983; Menaghan \& Parcel, 1990; Scanzoni \& Szinovacz, 1980). Scanzoni and Szinovacz and Greaves, Zvonkovic, Evans, and Hall (1995) considered power bases that are measured by which partner has the greater educational attainment, as well as the greater percentage of income and asset ownership within the marital unit. Resource theory has traditionally posited that in the marriage relationship both individuals contribute equally in various ways to the fulfillment of the marriage. In practice, this marital approach should foster an environment of mutual respect and consultation in decision making. Inevitably, however, one partner typically begins to contribute greater resources (e.g., income, wealth, etc.) than the other, which results in an imbalance of power and thus a greater influence in the decision-making process. This discrepancy results in the realization that one partner contributes greater resources, and as a result of the recognition of this imbalance, feelings of indebtedness by the receiving partner often arise.

There have been many changes in U.S. society since Blood and Wolfe's (1960) original research. Even then, Blood and Wolfe acknowledged the changing landscape of America's social roles when they stated:

Everybody knows that the balance of power between men and women has been changing. Has it changed because our ideas about how men and women ought to treat each other have changed? Or has it changed because the comparative resources of American men and women have changed? (p. 13-14)

The DPI, as a power index assessment tool, was developed to help researchers better understand these changing dynamics. The DPI has been and continues to be used in research involving power within a couple's relationship. The measure consists of eight questions concerning who makes decisions about how money is spent, how healthcare is chosen, and career choices. The measure was developed as a means to examine the relative balance of power that exists between husbands and wives. The eight questions in the index were chosen because they are representative of decisions faced by most married couples. Blood and Wolfe assumed that husbands and 
wives would consult each other prior to making a decision but that usually one person would make the final decision. The eight questions included in the DPI are as follows:

1. Who usually makes the final decision about what car to get?

2. Who usually makes the final decision about whether or not to buy life insurance?

3. Who usually makes the final decision about what house or apartment to take?

4. Who usually makes the final decision about what job your spouse should take?

5. Who usually makes the final decision about whether or not you should go to work or quit work?

6. Who usually makes the final decision about how much money your family can afford to spend per week on food?

7. Who usually makes the final decision about what doctor to have when someone is sick?

8. Who usually makes the final decision about where to go on vacation?

Another dimension of Blood and Wolfe's (1960) research involved decision making in the family and the role of differentiation between the husband and wife. Their research led them to report that the level of spousal educational attainment was a primary factor in the determination of who monitors a couple's financial matters. Davis and Rigaux (1974) extended this research by considering the influence applied by husbands and wives during three different stages of the decision-making process. These stages included (a) problem recognition, (b) internal and external search, and (c) final decision making. Two of the twenty-five economic decisions they observed were the objectives and forms of saving. While both of saving decisions tend to be traditionally made jointly, Davis and Rigaux examined the role of specialization in three different stages of the decision-making process and the relative influence of each spouse. Both of these financial decisions were considered to be more heavily influenced by the husband in the first two stages of the decision-making process. Davis and Rigaux stated that "interestingly, the five decisions for which wives' influence is greater in the final stages are those which are the most husband influencedthat is, garden tools, car, life and other insurance and forms of savings." Unexpectedly, their research showed that instead of the husbands' influence continuing to increase into the final stage, there seemed to be a regression to the mean.

Another implication of this shift in influence toward the wife might be extended to resource theory itself if Davis and Rigaux (1974) had considered the educational attainment, income, and occupational status of each spouse. Blood and Wolfe (1960) stated that "a resource may be defined as anything that one partner may make available to the other, helping the latter satisfy his needs to attain his goal" (p. 12). This definition notwithstanding, nearly all of the research concerning the theory, as well as the findings by Blood and Wolfe, indicates that "power within relationships rests on the ability to control economic resources" (Greaves et al., 1995, p. 49). In the 1960s and 1970s this implied that the husband controlled the power. More recent research suggests that power within the relationship is not necessarily gender biased, but rather, as suggested by Greaves et al., economic. Unfortunately, without controlling for the education and income of the wife, the cause of this shift in influence, as of this writing, is unknown.

\section{Risk Tolerance And The SCF}

Risk tolerance has been defined in numerous ways; however, within the financial risk-tolerance literature, the concept is typically "conceptualized as a personality trait ... defined as the amount of risk that an individual is willing to accept in the pursuit of some goal" (Roszkowski \& Davey, 2010, p. 43). As Roszkowski and Davey pointed out, a vast number of household decisions involve taking financial risks. Although an important factor within the decision-making process, very little is known about how decision power and risk tolerance relate to each other.

A modified version of the risk-tolerance question from the Survey of Consumer Finances (SCF) was used in this study in order to help address this query. The SCF question has been used as a measure of financial risk tolerance in numerous publications in the household and consumer finance literature; however, there has been only one published study that has empirically examined the validity and reliability of the SCF measure (Grable \& Lytton, 2001). In their study, Grable and Lytton compared the SCF question to a multidimensional financial risk-tolerance assessment measure (see Grable \& Lytton, 1999). In commenting about the validity of the SCF question, they stated 
that the "face validity of the item is well founded, while the consistency of the results associated with the use of the item tends to support its construct validity" (Grable \& Lytton, 2001, p. 46). In addition, they found that the concurrent validity coefficient was .54 when compared to the multidimensional index. This SCF risk question has been used as a dependent variable in several studies (e.g., Finke \& Huston, 2003, 2004; Hanna, Gutter, \& Fan, 2001; Hanna \& Lindamood, 2005; Schooley \& Worden, 1996; Yao \& Hanna, 2005); further, the reliability of the response pattern with various administrations of the SCF question shows that the measure has "remained relatively stable suggesting that the item is somewhat reliable" (Grable \& Lytton, 2001, p. 43).

In this study, the following version of the SCF question was used to query respondent's willingness to engage in a financial risk-taking behavior. This question differed from the original SCF item by removing the phrase "and your (spouse/partner)" from the question. The modified version reads as follows:

Which of the statements on this page comes closest to the amount of financial risk that you are willing to take when you save or make investments?

1. Take substantial financial risk expecting to earn substantial returns

2. Take above average financial risks expecting to earn above average returns

3. Take average financial risks expecting to earn average returns

4. $\quad$ Not willing to take any financial risk

\section{Examples Of SCF Item Usage}

In 1996, Schooley and Worden examined whether or not the "relative risk aversion (RRA) calculated from the composition of a household's portfolio and RRA reported by the household in terms of willingness to take financial risk were directly related and can be used interchangeably to proxy risk aversion" (p. 87). The RRA reported by the household was based on the SCF risk question. A one-way ANOVA was used to test whether the means of the calculated RRA were significantly different across the households' reported attitude toward risk taking as measured by the SCF question. The results showed significance across the four response categories of the SCF measure and were in the expected order of size, as shown in Table 1 below. These results indicate that the households surveyed were able to identify their relative level of risk tolerance. The results of a $t$-test performed to determine the differences between the four categories showed that there was no significant difference between the two categories of "substantial" and "above average" however; there were significant differences between the other categories. The authors noted the high ratio of risky assets to wealth for the "none" category. Schooley and Worden suggested that a possible explanation could be due to the fact that there was not a category for "less-than-average" financial risk in the SCF measure.

Table 1. Mean Values of Risky Assets To Wealth Across Reported Risk Aversion

\begin{tabular}{|l|c|c|c|c|c|}
\hline \multicolumn{1}{c}{$\begin{array}{c}\text { Risk } \\
\text { Measure }\end{array}$} & Substantial & $\begin{array}{c}\text { Above } \\
\text { Average }\end{array}$ & Average & None & $\begin{array}{c}\text { Test } \\
\text { Statistic }\end{array}$ \\
\hline Risky Assets/Wealth & .982 & .941 & .858 & .722 & $33.04 *$ \\
\hline (\% of sample) & $(3.9 \%)$ & $(9.1 \%)$ & $(41.1 \%)$ & $(45.9 \%)$ & \\
\hline
\end{tabular}

$* F$ statistic indicates significant differences in mean values across groups, at 1 percent level, $n=2239$. Risky assets are those measured assets whose cash flows are uncertain (including human capital).

It is important to note that the SCF risk question has come under scrutiny as a comprehensive measure of risk taking. Hanna, Gutter, and Fan (2001, p. 54) noted that different measures of risk tolerance tend to not be "linked to the concept of risk tolerance in economic theory," and that the SCF measure might reflect "a combination of current situation and/or the investor's limited information." On the other hand, there is some evidence to indicate that "the SCF risk-tolerance measure may be a useful indicator of intentions in investing, and may be superior to measures of risk tolerance based on actual portfolio allocation, since many households have no investment assets" (Yao \& Hanna, p. 69, 2005). To summarize, while the SCF question may not be ideal as a global measure of risk tolerance, or even a broad measure of financial risk tolerance, the question does appear to be an effective tool for evaluating tolerance for investment risks (Hanna \& Lindamood, 2005). 


\section{Decision Making And Risk Tolerance At The Household Level}

As suggested in the introduction to this study, very little research has been focused on decision power within couple relationships as it relates to both risk tolerance and risk taking at the household level. One notable exception was a paper published by Jianakoplos and Bernasek (2008) in which the SCF risk question was used to examine the relative bargaining power hypothesis and the pooled resources hypothesis. The relative bargaining power hypothesis states that the person within a couple relationship who controls more family resources - typically income - has greater power when making household decisions. If true, this would imply that because men typically earn more than women they should hold greater bargaining power, and as such, men should have a greater say in the allocation of resources. In other words, the husband's risk tolerance should dominate that of the wife. In their study, however, Jianakoplos and Bernasek found that household financial risk taking is more consistent with the pooled resources hypothesis, so that even if women exhibit relative income gains, compared to their husbands, the level of decision power is likely to remain stable.

In an earlier study, Bernasek and Shwiff (2001) noted that women not only are less risk tolerant than men but that women are more conservative investors in general. Their findings were unique in addressing the issue of household decision making. They found that married women tend to react in an opposite way from their spouse in terms of risk tolerance. This relationship with marital status, gender, and risk tolerance was also noted by Arano, Parker, and Terry (2010). Specifically, in cases where a female spouse's husband had an average or higher level of risk tolerance, the female spouse was reported to be less willing to take risks. The strong relationship among decision and bargaining power, income, and risk tolerance was also documented by Bernasek and Bajtelsmit (2002). They found that a woman's role in household financial decision making increased as the wife's share of income increased.

\section{RESEARCH HYPOTHESES}

The questions underlying this research were as follows: (1) what is the relationship between decision power and portfolio risk level? and (2) what is the relationship between decision power and risk tolerance in heterosexual couple households? The specific research hypotheses developed to test these questions were as follows:

$\mathbf{H}_{1}$ : The level of decision power within a household is related to the household's portfolio risk level.

$\mathbf{H}_{2}$ : The level of decision power within a household is related to the household's financial risk tolerance level.

\section{DATA AND METHODOLOGY}

Data for this study were collected primarily from faculty and staff at colleges and universities in Texas and New Mexico. One hundred and seventy five couples completed a 38 question web-based survey consisting of the Blood and Wolfe (1960) DPI, the SCF risk-tolerance question, and demographic queries, including educational attainment and selected financial information.

\section{Data Analysis Method}

A combination of correlation analyses, t-tests, and general linear modeling (GLM) were undertaken to test the research questions and associated hypotheses. The GLM method was chosen as the preferred methodological approach because this statistical procedure allows for individual differences to be controlled and for possible interactions among predictor variables to be measured. In this study, a Type III sum-of-squares method GLM was employed. The Type III approach is appropriate when an unbalanced model with no missing cells is tested. Two GLM tests were conducted. The first GLM examined portfolio risk as the variable of study and the second with risk tolerance as the key outcome variable. 


\section{Measures}

Portfolio risk level, the variable of interest in the first hypothesis, was formulated by a panel of experts. The variable was categorized into three levels of risk: (a) conservative, (b) moderate, and (c) aggressive. The first step in creating this variable was to obtain the percentages of assets held in five categories from each of the survey respondents. The categories consisted of (a) stock or equity funds; (b) bonds or bond funds;;(c) investment property and/or real estate investment trust; (d) cash; and (e) "other" investments which consisted of collectibles, commodities, and business ownership. The overall percentage data were based on total portfolio assets, including individually and jointly owned assets. A Delphi panel of five raters independently examined the portfolio of each participant and rated it as conservative (coded 1), moderate (coded 2), or aggressive (coded 3). The inter-rater reliability based on Cronbach's alpha was .89 for both husbands and wives. Finally, an overall portfolio risk level score (taken from the five categories of assets) was created for wives and husbands, separately, by obtaining the mean score for each respondent across all five raters.

The second hypothesis was tested with a risk tolerance variable- the SCF risk-tolerance question. As discussed earlier, this single item question was modified in order to ask an individual about their financial risk tolerance. The question was recoded for the analysis so that those with the highest level of risk tolerance (i.e., willing to take substantial financial risk) were given the highest score (4). The scoring of the SCF measure was as follows: no risk $=1$; average risk $=2$; above average risk $=3$; and substantial risk $=4$. The mean and standard deviation for wives and husbands is shown in Table 2.

The measure of decision power was derived from the DPI. The summated variable consisted of eight Likert-type scaled items asking each of the members of the dyad (i.e., husbands and wives separately) to rate how often the person made the final decision in each of the following situations: insurance, housing, employment, budgeting, health care, and other areas. Scores on each item were scaled as follows: wife only $=1$; wife more than husband $=2$; husband and wife the same $=3$; husband more $=4$; and husband always $=5$. The total DPI score was calculated by summing the scores from each of the eight individual questions, subtracting 8 , and multiplying by 100/32, which transformed the scores into a 0 to 100 scale. In addition, a DPI score for the couple was computed by obtaining the mean score of both the husband's and wife's scores. Table 2 reports the mean and standard deviation scores for wives and husbands.

\section{Demographic Variables}

Data on the following demographic measures were obtained separately for each husband and wife: age, relative income, asset ownership, and education. A mean score for the couples age computed since their ages were highly correlated $(\mathrm{r}=.94, \mathrm{p}<.01)$. The education variable was coded as a 3-category measure: (a) high school diploma or Associate Degree/Trade School Degree; (b) university degree; and (c) post-graduate degree.. The independent variable of asset ownership was created separately for the husband and wife in each dyad based on the percentage of assets owned by each. A three-category asset ownership variable was then created and coded as follows: (a) wife's assets exceed husband's assets $=-1$; (b) husband's and wife's assets equal $=0$; and (c) husband's assets exceed wife's assets $=1$. Frequencies for the variables of interest in this study can be found in the results section which follows.

\section{RESULTS}

Means and standard deviations for the dependent variables, the independent variables, and age for husbands and wives are displayed below in Table 2. Of the 175 males in the sample, 43.4\% $(\mathrm{n}=76)$ held a post-graduate degree, $32.0 \%(\mathrm{n}=56)$ had a bachelor's degree, and $24.6 \%(\mathrm{n}=43)$ reporting having a high/trade school or associate's degree. Of the 175 females in the sample, $38.9 \%(n=68)$ had a post-graduate degree, $34.9 \%(n=61)$ held a bachelors degree, and $26.3 \%(n=46)$ had a high/trade school or associate's degree. 
Table 2. Means and Standard Deviations For Independent Aand Dependent Variables

\begin{tabular}{|c|c|c|c|c|c|c|}
\hline \multirow[b]{2}{*}{$(N=175)$} & \multicolumn{2}{|c|}{ Couple } & \multicolumn{2}{|c|}{ Wife } & \multicolumn{2}{|c|}{ Husband } \\
\hline & M & SD & $\mathbf{M}$ & SD & $\mathbf{M}$ & SD \\
\hline \multicolumn{7}{|l|}{ Dependent Variables } \\
\hline Portfolio risk level & & & 2.01 & .68 & 1.92 & .72 \\
\hline SCF Risk Tolerance & & 2.20 & .61 & 2.57 & .77 & \\
\hline \multicolumn{7}{|l|}{ Independent Variables } \\
\hline Decision Power Index & & 48.89 & 9.80 & 48.85 & 8.30 & \\
\hline Age & & 41.26 & 11.27 & 43.35 & 11.62 & \\
\hline Couple's Age & 42.31 & 11.29 & & & & \\
\hline
\end{tabular}

The frequency distribution and percentages of the portfolio risk-level scores, based on Delphi estimates, for husbands and wives is shown below in Table 3. Percentages and frequency distributions for the SCF risk-tolerance variable are found in Table 4 below. Note that the distribution of scores differed from those reported by Schooley and Worden (1996). In this study, less than $10 \%$ of respondents indicated being willing to take no risk, while in the Schooley and Worden study that percentage was over $45 \%$.

Table 3. Frequency And Percentages For Portfolio Risk Level Scores

\begin{tabular}{|c|c|c|c|c|}
\hline \multirow{2}{*}{$\begin{array}{l}(\mathrm{N}=175) \\
\text { Score }\end{array}$} & \multicolumn{2}{|c|}{ Husband's } & \multicolumn{2}{|c|}{ Wife's } \\
\hline & $\mathbf{N}$ & $\%$ & $\mathbf{N}$ & $\%$ \\
\hline 1.00 & 34 & 19.4 & 22 & 12.6 \\
\hline 1.20 & 10 & 5.7 & 17 & 9.7 \\
\hline 1.40 & 16 & 9.1 & 8 & 4.6 \\
\hline 1.60 & 12 & 6.9 & 18 & 10.3 \\
\hline 1.80 & 21 & 12.0 & 18 & 10.3 \\
\hline 2.00 & 9 & 5.1 & 9 & 5.1 \\
\hline 2.20 & 13 & 7.4 & 13 & 7.4 \\
\hline 2.40 & 21 & 12.0 & 31 & 17.7 \\
\hline 2.60 & 4 & 2.3 & 1 & .6 \\
\hline 2.80 & 7 & 4.0 & 3 & 1.7 \\
\hline 3.00 & 28 & 16.0 & 35 & 20.0 \\
\hline Total & 175 & 100.00 & 175 & 100.00 \\
\hline
\end{tabular}

Table 4. Frequencies And Percentages For SCF Risk Tolerance Variable

\begin{tabular}{|l|r|r|r|r|}
\hline (N = 175) & \multicolumn{2}{|c|}{ Husband's } & N & \%ife's \\
\hline SCF Risk Score & N & \% & 11 & 6.3 \\
\hline No Risk & 15 & 8.6 & 73 & 41.7 \\
\hline Average Risk & 114 & 65.1 & 72 & 41.2 \\
\hline Above Average Risk & 42 & 24.0 & 19 & 10.9 \\
\hline Substantial Risk & 4 & 2.3 & & \\
\hline & & & 175 & 100.00 \\
\hline Total & 175 & 100.00 & & \\
\hline
\end{tabular}

\section{The Effect Of Decision Power On Portfolio Risk Level}

Prior to conducting a multivariate analysis to examine the impact of decision power on portfolio risk level, a correlation analysis was performed. This analysis was used to test for associations between and among the dependent variables of interest in this study and the independent variables. Potential between-subjects factors and independent variables, including gender, age, education, asset ownership, relative income, personally owned assets, and spouse's assets were also examined. Correlations among all of the independent variables and the portfolio risk level measures were obtained in order to determine whether any of the associations might suggest the presence of multicollinearity, which might limit the validity of any further multivariate tests. 
Results from this analysis showed that the DPI/male and the DPI/female were significantly positively correlated, $(r=.61, p<.01)$, that education/male and education/female showed a significant positive correlation $(r=$ .30. $p<.01$ ), and that the portfolio risk level variable/male showed a significant positive correlation with the portfolio risk level variable/female $(r=.34, p<.01)$. The portfolio risk level variable/female was moderately, and negatively, correlated with the DPI/female $(r=-.17, p<.05)$. Since low to moderately significant correlations were found among the independent variables and the portfolio risk level measures, multicollinearity did not appear to be an issue. Further, results of a paired-sample t-test comparing the husband's and wife's portfolio risk level measure were insignificant $(t=-1.47, d f=174, p<.15)$, leading to the conclusion that a more robust multivariate analysis could be undertaken to test the research hypotheses.

A general linear model (GLM) test was performed, with male and female portfolio risk level variables representing the variables of interest, with gender as a within-subjects factor. The between-subjects factors included: level of education (male, female), and asset ownership (wife owns more, equal ownership, husband owns more). The model included the following variables: DPI/male and DPI/female, relative income, and couple's age. Results of the GLM analysis and the tests of within-subject effects showed only a significant interaction between gender and wife's level of education: (Wilks' $\lambda=.96, F,(2,162)=3.44, p<.05$ ). This was interpreted to mean that the way in which education influences portfolio risk level differs as a function of gender. However, the test of between-subjects effects showed a main effect for DPI/Female $(F,(1,162)=5.52, p<.05)$ but not for DPI/male. This indicates that differences in portfolio risk level are affected by DPI/female. There was no main effect for wife's level of education in the tests of between-subjects effects. This means that wife's level of education may have only had an impact on portfolio risk level when gender is taken into account. This result is graphically illustrated in figure 1 below.

Figure 1: Asset Allocation By Wife's Education

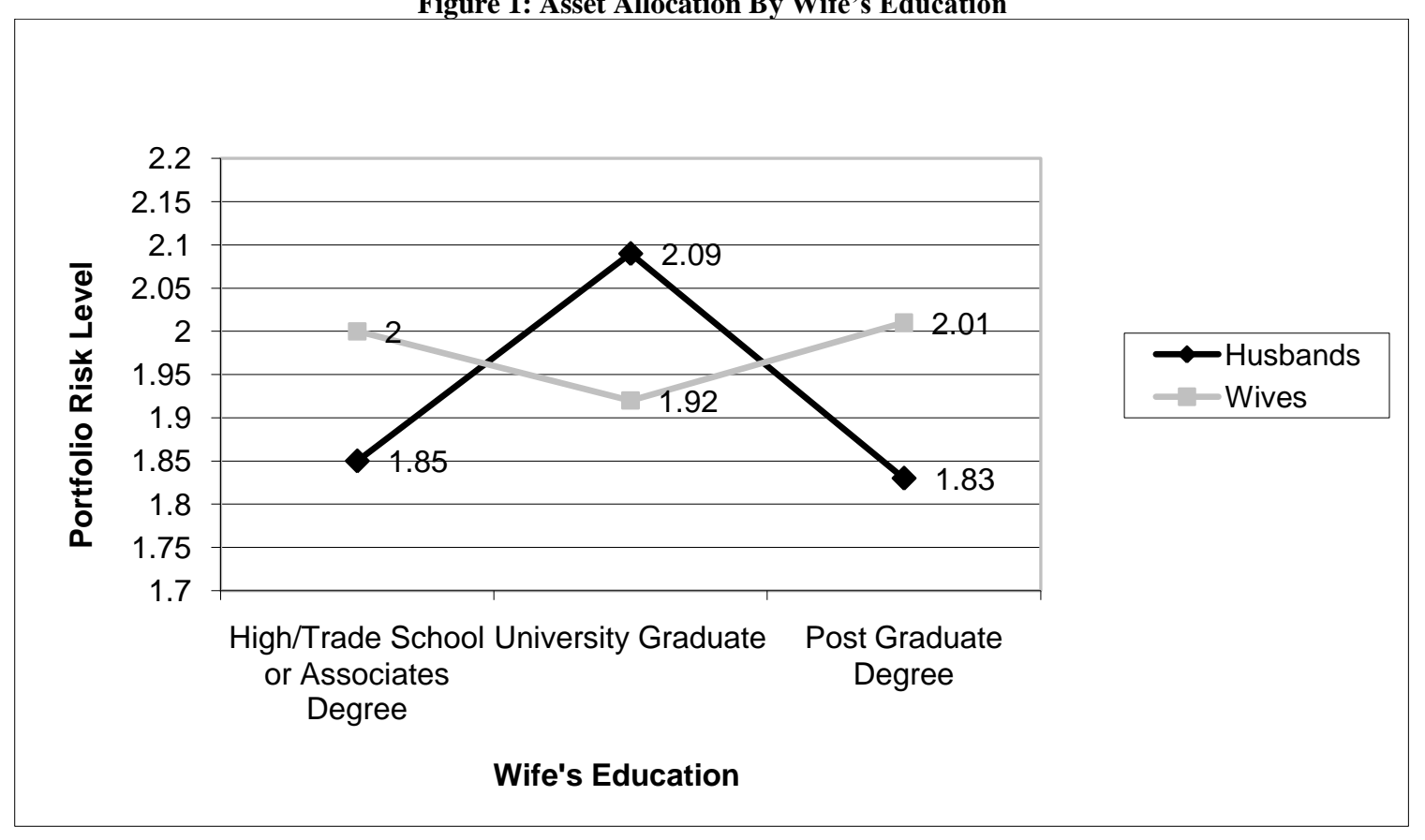

\section{The Effect Of Decision Power On Financial Risk Tolerance}

Similar to the test of the effect of decision power on portfolio risk, a GLM test was used to estimate the effect of decision power on financial risk tolerance. Prior to conducting the multivariate analysis examining the effect of decision power on financial risk tolerance, a separate correlation analysis was performed with the independent variables (DPI/male, DPI/female), the dependent variables (SCF risk/male, SCF risk/female), and the 
between-subjects factors and independent variables including: gender, level of education (male and female), rural v. urban (male and female), age, relative income, personally owned assets of each spouse, and jointly owned assets.

The results of the analysis showed that the DPI/male and SCF risk/male were moderately correlated with one another $(\mathrm{r}=.16, \mathrm{p}<.05)$. No other significant correlations were noted among the remaining independent variables. It was determined, therefore, that multicollinearity was not a significant issue within the model. In addition, the presence of a significant correlation between one of the dependent variables (SCF risk/male) and one of the independent variables (DPI/male) suggested that a multivariate analysis would be useful in determining whether or not this variable predicted differences in risk tolerance along with a set of other independent variables/betweensubjects variables.

Results of a paired-sample $t$-test comparing the SCF risk/male variable and the SCF risk/female variable were significant $(t=6.01, d f=174, p<.01)$. Husbands scored significantly higher on this measure $(\mathrm{M}=2.57)$ than did wives $(M=2.20)$, indicating that husbands were more likely to be willing to take higher degrees of risk than their wives. The GLM analysis was performed, with husband's and wife's SCF risk variables representing the dependent variable, and gender as the within-subjects factor. The between-subjects factors included: education (male and female), and asset ownership (i.e., wife owns more, equal ownership, husband owns more). The model included $\mathrm{DPI} /$ male and DPI/female, along with relative income and couple's age.

Results from the GLM analysis, and the test of both within-subject effects and contrast, showed a significant interaction between gender and asset ownership (Wilks' $\lambda=.95, F,(2,162)=3.82, p<.05)$. This interaction is illustrated in figure 2 below.

Figure 2: SCF Risk By Ownership (Husband And Wife)

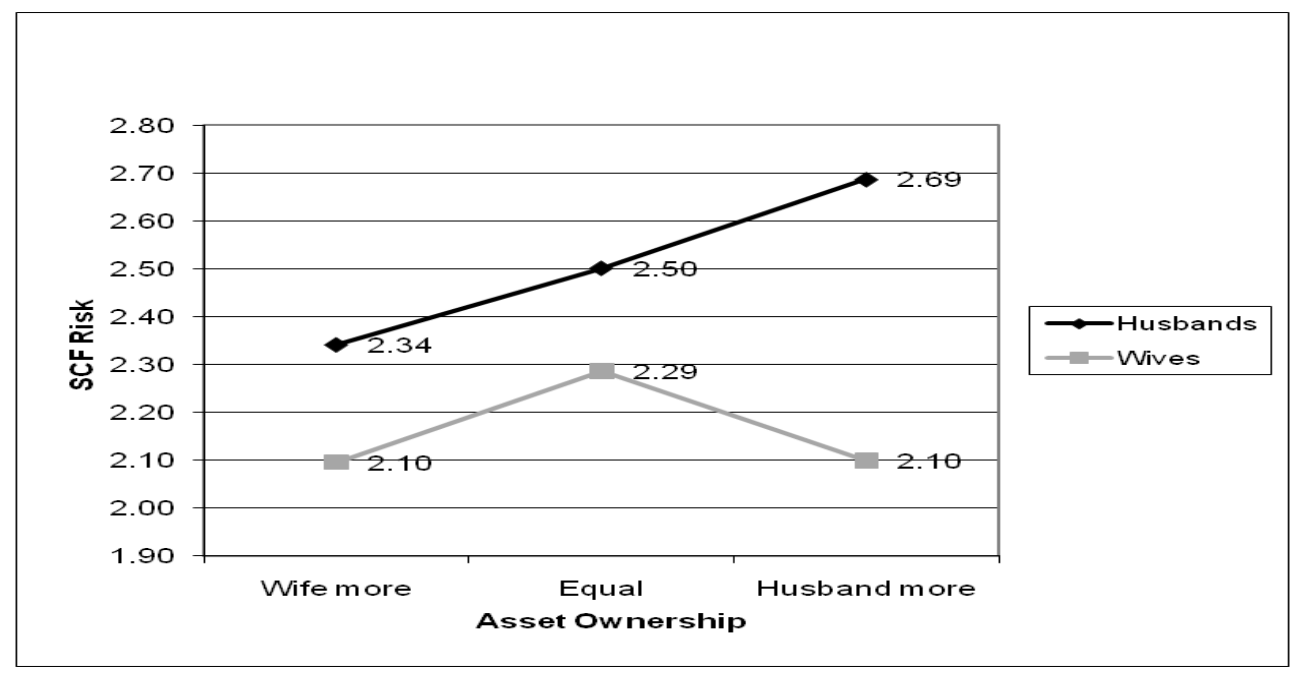

The results from the test, particularly the interaction, were interpreted to mean that the way in which asset ownership influences financial risk tolerance differs as a function of gender. This is consistent with the findings of the paired-sample $t$-test where a significant difference was found between male and female spouses on the SCF risk measure. However, tests of between-subjects effects showed significant main effects for both DPI/female $\left(F_{1,162}=\right.$ $3.94, p<.05)$ and DPI/male $(F, 1,162=4.68, p<.05)$. This indicates that differences in financial risk tolerance were affected separately by each husband's and wife's level of decision power. Finally, a significant main effect was found for wife's education $\left(F_{1,162}=5.72, p<.01\right)$, indicating that financial risk tolerance was directly affected by the wife's educational attainment level. The level of risk tolerance was not moderated by gender, as was found in the portfolio risk level analysis. This is illustrated in figure 3 below. 
Figure 3: SCF Risk By Wife's Education

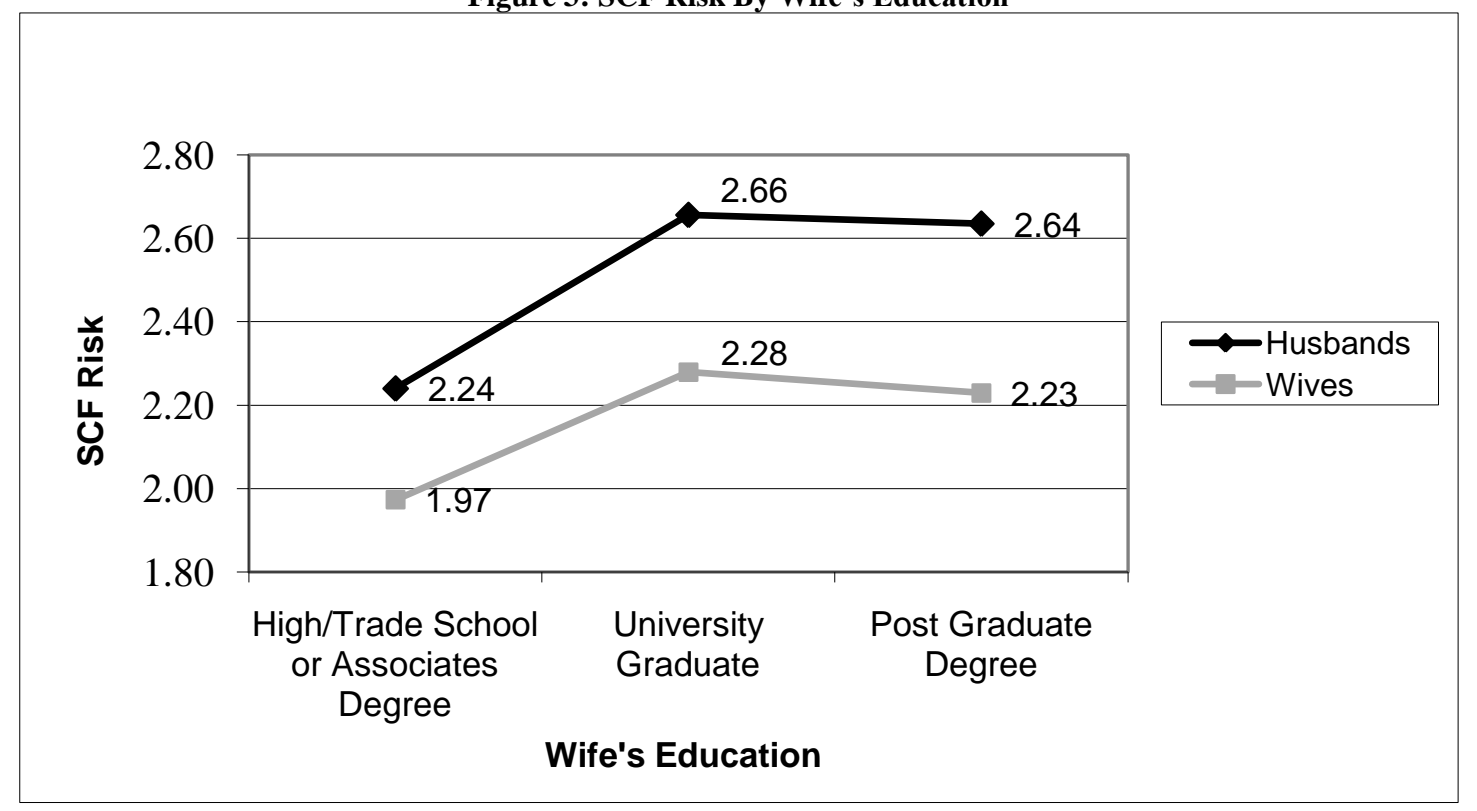

\section{DISCUSSION}

The purpose of this research was to extend the theoretical foundation of resource theory to the way couples undertake the decision-making process, particularly in the context of each spouse's financial risk tolerance. The test of the first hypothesis showed that the impact of decision power on portfolio risk level was mixed. The findings indicated a main effect between decision power for wives and portfolio risk level. As such, the hypothesis was only partially supported.

Even though the preliminary statistics showed significant correlations between husband and wife DPI scores, educational attainment, and portfolio risk levels, it was determined, using a GLM method, that a husband's portfolio risk level was not impacted by decision power. The inverse reaction between the husband's and the wife's portfolio risk intensity to the wife's education level may be a function of the wife's relative income.

It is possible that the significant correlation between the husband's and wife's education level also impacted the variance in portfolio risk level. Past literature has shown education to be a significant predictor of risk tolerance. Even though risk, as measured by portfolio asset allocations, is not a direct risk-tolerance measure, it could reflect the application of attitudes towards risk tolerance. However, the finding for women is somewhat in conflict with resource theory when combined with previous research on risk tolerance. Several recent studies have identified education as a significant predictor of risk tolerance and have shown that with increases in educational attainment risk tolerance scores also increase (Grable \& Lytton, 1998; Hariharan, Chapman, \& Domian, 2000; Hanna \& Lindamood, 2005; Yao \& Hanna, 2003, 2005).

Contrary to the finding related to the first hypothesis is the main effect found between the independent variables of the wife's educational level and the SCF score for both husbands and wives when examining the impact of decision power on risk tolerance. This finding indicates that as educational attainment increases to university graduate or higher there is a corresponding increase in the SCF risk tolerance scores for both spouses. This is supportive of the statement by Blood and Wolfe (1960) concerning the changes in relative resources by husbands and wives. In this case, an increase in the wife's relative resources through higher education affects the risktolerance score for both herself and her husband. 
The asset ownership variable in this research was examined using a different approach than in previous studies. Instead of looking at the total amount of assets, this research examined the percentage of individual ownership of assets. In this examination, as in previous literature, husbands had a greater degree of risk tolerance than their wives. The asset ownership variable was found to have a different effect on wives than on their husbands. The wife's SCF scores were at their highest when the assets were owned jointly. The husband's SCF scores continued to increase as the degree of ownership increased from the wife owning more, to jointly owned and was the highest when the husband own more of the assets.

This research is the first to examine the effect of decision power on financial risk tolerance. Within this context, the second hypothesis, which stated that decision power is a predictor of financial risk tolerance, was supported by the findings from this research. The implication of this finding is noteworthy when considering the fact the husband's and wife's decision power scores were significantly correlated, yet the results showed that decision power impacted risk tolerance separately for each individual.

There are many implications associated with this research for financial professionals and researchers working in the personal and household finance domain. The importance of the wife's education was shown to be significant using different measures of risk tolerance in both hypotheses. This was especially true in the test of the first hypothesis when the wife had a post graduate degree and was found to have a more risky asset allocation. In the test of the second hypothesis, the findings were similar to previous studies using the SCF risk tolerance measure which showed an increase in risk tolerance as educational attainment increases. However, this study found that only the wife's education had a significantly positive impact on risk tolerance as measured by the SCF. As such, financial professionals should pay close attention to the education of wives due to the potential for changes in risk tolerance. Since decision power has not been previously examined, future research should consider its role in the financial risk tolerance of couples.

\section{CONCLUSION}

The chief limitation of this research comes from the data used, which were a convenience sample gathered from more highly educated couples working at universities located in two southwestern states. Even though this limitation exists, convenience samples, such as the one used in this study, are often used exploratory research when evaluating untested hypotheses. The focus of this research was on the effect of decision power within couples as they make financial decisions. The analysis found three significant main effects and two significant interaction effects. In the test of the first hypothesis, there was a significant interaction between gender and the wife's level of education. This indicates that the influence of education on portfolio risk level is different between husbands and wives. There was also a main effect for the decision power of wives which shows the impact of decision power on the portfolio risk level.

The test of the second hypothesis found a significant interaction between gender and asset ownership. This again shows a gender difference between husbands and wives but this time as it applies to the influence that asset ownership has on financial risk tolerance. This was affirmed by the paired $t$-test which showed a significant difference in the SCF scores of both members of the dyad. This was followed by a significant between-subjects main effect for both husbands' and wives' decision power. This is perhaps the most significant finding from this research because decision power has not been previously considered as an influence on financial risk tolerance. Once again, as with portfolio risk level, there was a significant main effect of the wife's education. This connotes the direct influence of the wife's education on financial risk tolerance that was not mitigated by gender.

The findings of this research were only somewhat supportive of assertions made by Scanzoni and Szinovacz (1980) and Greaves et al. (1995) who studied resource theory. Their research considered power bases that are measured by greater educational attainment as well as greater percentage of wealth. While the data are insufficient to determine the degree of variance within the marital unit, there are two results in this research that were in conflict to previous findings reported in the literature. Regarding the first hypothesis, a conflict was found in the inverse reaction that the husband's and wife's portfolio risk level scores demonstrated due to the influence of the wife's educational attainment. This is particularly evident as the wife's scores decreased as educational attainment increased to university graduate. Regarding the second hypothesis, there was a conflict where the wife owned more 
assets than her husband. Based on previous risk tolerance literature, the wife's risk tolerance scores should have been greater when she owned more assets.

In conclusion, future research should investigate more thoroughly the exact impact educational attainment has on both husbands and wives. Perhaps this research was tainted by the abundance of highly educated participants. However, a substantial number of individual investors have higher levels of education. The influence of decision power, as well as other behavioral characteristics, should be further examined in order to gain a greater depth of understanding into the complexities of financial decision making within couples.

\section{AUTHOR INFORMATION}

John Gilliam, Ph.D., CFP®, CLU is an Assistant Professor in the Division of Personal Financial Planning at Texas Tech University. His entry into academic life is strongly influenced by over 30 years of professional experience as a financial advisor. John incorporates his myriad experiences as he teaches risk management, insurance planning and employee benefits. His research and academic interest include the assessment of financial risk tolerance, financial risk tolerance in couples, the impact of behavioral heuristics and biases in financial planning, Intra-cohort differences among Baby boomers, and health care considerations during retirement. John currently serves on the national board of the Society of Financial Service Professional, is a co-chair of the Society's University Partners Program sub-committee and a committee member of the Society's Young Professionals Development Committee. He is a Certified Financial Planner ${ }^{\mathrm{TM}}$, Charter Life Underwriter and Chartered Financial Consultant.

John Grable, Ph.D., CFP®, RFC holds the Vera Mowery McAninch Professor of Human Development and Family Studies professorship at Kansas State University. He is the Certified Financial Planner, Board of Standards Inc. and International Association of Registered Financial Consultants registered undergraduate and graduate program director at Kansas State University. Dr. Grable also serves as the Director of The Institute of Personal Financial Planning and Co-Director of the Financial Therapy Clinic at K-State. Dr. Grable served as the founding editor for the Journal of Personal Finance, and he is currently the co-editor of the Journal of Financial Therapy. Dr. Grable has served on the Board of Directors of the International Association of Registered Financial Consultants (IARFC), as Treasurer and President for the American Council on Consumer Interests (ACCI), and as Treasurer for the Financial Therapy Association. He was the recipient of the prestigious Cato Award for Distinguished Journalism in the Field of Financial Services, the IARFC Founders Award, and the Dawley-Scholer Award for Faculty Excellence in Student Development.

Vickie L. Hampton, Ph.D., CFP® is a Professor of Personal Financial Planning and Chair of the Department of Applied and Professional Studies at Texas Tech University. She has authored numerous articles on career development and related issues in the financial planning profession, determinants of success on the CFP® Certification Examination, and financial planning guidelines and benchmarks for measuring financial well-being of families. Hampton teaches Personal Financial Planning classes at the undergraduate and graduate levels. Currently, Hampton is President-Elect of the Academy of Financial Services and a member of the NEFE Academic Advisory Council. Over the past ten years, Vickie has been active on national boards serving on the Certified Financial Planner (CFP) Board of Governors, the CFP Board of Examiners, the Board of Trustees for the American College, and the Academy of Financial Services Board. She chaired the 1999 CFP Board Job Analysis Committee and was on the steering committee for the AFS and CFP Board Model Financial Planning Curriculum Project. Hampton joined the Texas Tech faculty and the Center for Financial Responsibility in 1999. She received her M.S. and Ph.D. degrees in Family and Consumption Economics at the University of Illinois - Urbana. Before coming to Texas Tech, Dr. Hampton taught and conducted research in personal financial planning at the University of Texas - Austin.

\section{REFERENCES}

1. Amato, P.R., \& Booth, A. (1995). Changes in gender role attitudes and perceived marital quality. American sociological review, 60, 58-66.

2. Arano, K., Parker, C., \& Terry, R. (2010). Gender-based risk aversion and retirement asset allocation. Economic Inquiry, 48, 147-155. 
3. Beavers, R. (1982). Healthy, midrange, and severely dysfunctional families. I F. Walsh (Ed.), Normal family processes, (pp. 45-66). New York: Guilford.

4. Bernasek, A., \& Bajtelsmit, V.L. (2002). Predictors of women's involvement in household financial decision-making. Journal of Financial Counseling and Planning, 13(2), 39-47,

5. Bernasek, A., \& Shwiff, S. (2001). Gender, risk, and retirement. Journal of Economic Issues, 35, 345-356.

6. $\quad$ Blood, R. O., Jr., \& Wolfe, D.M. (1960). Husbands and wives. New York: Free Press

7. $\quad$ Blumstein, P., \& Schwartz, P. (1983). American couples: Money, work, sex. New York: Morrow.

8. Chaulk, B., Johnson, P. J., \& Bulcroft, R. (2003). Effects of marriage and children on financial risk tolerance: A synthesis of family-development and prospect theory. Journal of Family and Economic Issues, 24, 257-279.

9. Davis, H.L., \& Rigaux, B.P. (1974). Perception of marital roles in decision processes. Journal of Consumer Research, v.1, June, pp. 51-62.

10. Duda, H. F., Bruhin, A., Epper, T., \& Schubert, R. (2010). Rationality on the rise: Why relative risk aversion increases with stake size. Journal of Risk and Uncertainty, 40, 147-180.

11. Finke, M.S., \& Huston, S.J. (2004). Risk and myopic financial decisions. Journal of Personal Finance, 3(3), 99-112.

12. Finke, M.S., \& Huston, S.J. (2003). The brighter side of financial risk: Financial risk tolerance and wealth. Journal of Family and Economic Issues, 24, 233-257.

13. Gilliam, J.E., Goetz, J.W., \& Hampton, V.L. (2008). Spousal differences in financial risk tolerance. Journal of Financial Counseling and Planning, 19(1), 3-11.

14. Grable J.E., \& Lytton, R.H. (1998). Investor risk tolerance: Testing the efficacy of demographics as differentiating and classifying factors. Financial Counseling and Planning, 9(1), 61-74.

15. Grable J.E., \& Lytton, R.H. (1999). Financial risk tolerance revisited: the development of a risk assessment instrument. Financial Services Review, 8(1), 163-181.

16. Grable J.E., \& Lytton, R.H. (2001).Assessing the concurrent validity of the SCF risk tolerance question. Financial Counseling and Planning, 12(2), 43-52.

17. Greaves, K.M., Zvonkovic, A.M., Evans, L.S., \& Hall, L.D. (1995). Economic resources, influence, and stress among married couples. Family and Consumer Sciences Research Journal, v. 25, 47-70.

18. Hanna, S. D., Gutter, M., \& Fan, J. (2001). A measure of risk tolerance based on economic theory. Financial Counseling and Planning, 12(2), 53-60.

19. Hanna, S.D., \& Lindamood, S., (2005) Risk tolerance of married couples. Proceeding of the Academy of Financial Services.

20. Hariharan, G., Chapman, K.S., \& Domian, D.L. (2000). Risk tolerance and asset allocation for investors nearing retirement. Financial Services Review, 9, 159-170.

21. Hesse-Biber, S., \& Williamson, J. (1984). Resource theory and power in families: Life cycle considerations. Family Process, 23, 261-278.

22. Jianakoplos, N.A., \& Bernasek, A. (2008). Family financial risk taking when the wife earns more. Journal of Family and Economic Issues, 29, 289-306.

23. Lai, C. W. (2008). How retired households and households approaching retirement handle their equity investments in the United States. Journal of Family and Economic Issues, 29, 601-622.

24. Lee, J. (2007). Marriage, the sharing rule, and pocket money: The case of South Korea. Economic Development and Cultural Change, 55, 557-581.

25. Menaghan, E., \& Parcel, T. (1990). Parental employment and family life: Research in the 1980's. Journal of Marriage and the Family, 52, 1079-1098.

26. Roszkowski, M.J., \& Davey, G. (2010). Risk perception and risk tolerance changes attributable to the 2008 economic crisis: A subtle but critical difference. Journal of Financial Services Professionals, 64(4), 42-53.

27. Scanzoni, J., \& Szinovacz, M. (1980). Family decision-making.: A developmental sex role model. Beverly Hills, CA: Sage.

28. Schooley, D.K., \& Worden, D.D. (1996). Risk aversion measures: Comparing attitudes and asset allocation. Financial Services Review, 5, 87-99.

29. Ulker, A. (2009). Wealth holdings and portfolio allocation of the elderly: The role of marital history. Journal of Family and Economic Issues, 30, 90-108.

30. Yao, R., \& Hanna, S.D. (2003). Has financial risk tolerance changed since 1983? Consumer Interest Annual, 49, 1-14. 
31. Yao, R., \& Hanna, S.D. (2005). The effects of gender and marital status on financial risk tolerance. Journal of Personal Finances, 4 (1), 66-85.

32. Yilmazer, T., \& Lyons, A. C. (2010). Marriage and the allocation of assets in women's defined contribution plans. Journal of Family and Economic Issues, 31, 121-137.

\section{NOTES}

